\title{
Democratization of the Classroom through Teachers' Language Choices and Practices in Multilingual Classrooms of Zambia
}

\author{
Vigirio Bwalya* \\ The University of Zambia, Zambia
}

*Corresponding Author: Vigirio Bwalya, The University of Zambia, Zambia

\begin{abstract}
Considering the argument that Zambia is a multilingual country and that all the classrooms are multilingual while the current Language in Education Policy only mentions English as the language of instruction from grade five onwards, it was imperative to study the sociolinguistic situation of the grade 6 classrooms of Chibombo district and their corresponding teachers' language practices. The study was guided by the following objectives:(a) to establish the sociolinguistic composition of the classrooms and (b) to analyse teachers' language practices in selected grade six classrooms. The study utilised the sequential explanatory research design; a mixed methods approach that involves the collection and analysis of quantitative data first and then qualitative data. Cluster random, simple random and purposive sampling techniques were used to come up with 260 respondents of which 60 were grade 6 teachers and 200 were grade 6 pupils. The findings of the study showed that the grade 6 classrooms of Chibombo district were multilingual as teachers and learners came from diverse linguistic background and were able to speak more than one language. The findings also showed that while some teachers democratised their classrooms through the adoption of translanguaging as a pedagogic language practice, others insisted on monolingual language practices which resulted in symbolic violence. Thus, the study concluded that teachers' language practices did not fully democratise the classrooms due to semi-translanguaging.
\end{abstract}

Keywords: Democracy, Translanguaging, Symbolic Violence, Bilingual Education

\section{INTRODUCTION}

Since this study is about democratisation of a multilingual classroom with regard to teachers' language practices, it is imperative to briefly explain what multilingualism, democratisation of the classroom and a multilingual classroom are. Multilingualism refers to the presence and use of many languages in a given community (Simwinga, 2006). Gal (2007) defined multilingualism as the use of more than one language by an individual person or community. With regard to a multilingual classroom, it implies the presence of two or more languages in the classroom (Garcia, 2009). It follows then that a multilingual classroom constitutes language varieties spoken by individual learners and teachers from different speech communities. Thus, democratisation of the classroom as used in this study means the use of language varieties inherent in a multilingual classroom. Thus, teachers who use language varieties inherent in the classroom with the view of allowing pupil participation and epistemic access are called democrats. On the other hand, teachers who stick to monolingual/ monoglot language practices and ideologies in multilingual/multi-ethnic classrooms are understood to be undemocratic in this study.

This study was carried out in a rural district of Zambia called Chibombo. Zambia is a multilingual country because of the 73 ethnic groupings that are widely claimed as languages spoken in Zambia (Kashoki, 1978). However the exact number of languages and dialects spoken in the country is contested on many fronts. Kashoki's (1978) view that the 73 ethnic groupings are widely claimed as languages spoken in Zambia is shared by Africa (1980: 127-128) when he argued that "if the term tribe is seen as being coterminous with the notion of language or dialect, then the frequently articulated claim that Zambia has 73 languages and dialects is understandable." In trying to estimate the number of languages in Zambia, UNESCO (1964) gave the range of 50 to 100 vernacular languages whereas Grotpeter (1979) stated that there are 30 distinct languages in Zambia. Mwanza (2016: 39) clarified the number of languages and dialects present in the country when he stated that "Zambia has 73 dialects which can be collapsed into between 25 and 40 mutually intelligible 
languages. The 2000 census narrowed the number to 22 different languages (Gordon R, 2014). Despite the disparities in the number of languages spoken in Zambia, the multilingual state of the country remains undisputed. It was on the basis of the foregoing, and on the 2010 census' depiction of Central Province and Chibombo District in particular as multilingual places, that this study was carried out in Chibombo district.

In response to the multilingual nature of the country, the current Language in Education Policy states as follows:

The policy on education recognises the use of familiar Zambian languages as the official languages of instruction in the Pre-Schools and early Grades (Grades 1-4)... In Zambia, the seven (7) zone languages; Cinyanja, Chitonga, Icibemba, Kiikaonde, Lunda, Luvale and Silozi as well as the widely used community languages in specific school catchment areas will be used for this purpose..... English will be offered as a subject, beginning at Grade 2...... English will still remain as the official medium of instruction beginning at Grade 5 up to tertiary. (The Zambia Education Curriculum Framework, 2013: 19)

The policy gives room for multiple language practices in the lower primary schools when it states that "the 7 zone languages.... as well as well as the widely used community languages in specific school catchment areas will be used for this purpose" (ibid). But in the upper primary schools, the language policy states that "English will still remain as the sole official language of instruction beginning at grade 5 up to tertiary" (ibid). The foregoing Language in Education Policy which favours the use of local familiar languages for initial literacy learning in lower primary schools is viewed in this study as an attempt at the democratisation of multilingual classrooms whereas the use of English only starting at grade 5 is viewed in this study as an act that is linguistically undemocratic.

Bernstein (1973) postulated that the classroom is characterized by both horizontal and vertical discourses; horizontal discourse consists of unofficial languages while the vertical discourse consists of official languages. The interplay of both the horizontal and vertical discourses in ensuring epistemic access among pupils means the democratization of a multilingual classroom in this study. However, and as stated earlier, the current Language in Education Policy stipulates the use of English only in upper primary schools.

The use of the phrase "democratic language practices" in this study implies the multiple use of language varieties inherent in a multilingual classroom to enhance learning and teaching if the sociolinguistic context of the classroom demands so. It also means the recognition and respect for linguistic diversity in the classroom. A pedagogical language practice that encourages democratic language practices in a multilingual classroom is "translanguaging." On the other hand, the use of the term "undemocratic language practices" implies the use of one language as a medium of instruction in a multilingual classroom. It potentially results into symbolic violence which according to Bourdieu (1990) happens when the dominant language is legitimized through institutionalised discourse of education while other languages become illegitimate and excluded from official discourses.

\section{AIM OF THE STUDY}

The aim of the study was to analyse teachers' language practices and to determine whether these language practices are democratic or not.

\section{LITERATURE REVIEW AND CONCEPTUAL FRAMEWORK}

Democratisation of a multilingual classroom through the use of learners' languages and the respect for linguistic diversity reflects the system of education that is bilingual which Garcia (2009: 9) perceived as "an instance in which learners and teachers employ language practices that involve the use of multiple languages to ensure that the learners get the best from these practices."

Democracy in the classroom is synonymous with language practices that involve the use of language varieties inherent in the classroom. Commenting on "democracy," Totemeyer (1997) linked it to the use of people's language varieties in the classroom context. Legere (2002: 11) had a similar view of aligning language varieties with democracy when he postulated, "whenever the notion of democracy is focused on language variety people are familiar with or competent in is an inalienable component of that notion." In reference to democratisation, Mengisteab's (1996) stated that it is an ongoing process of striving to achieve and practice a socio-political arrangement that empowers the general 
population to control the decision making process. A multilingual classroom needs democratization because of its inherent language varieties that at times are hardly recognised and rarely used because of power relation that is unevenly shared.

John Dewey's concept of Democracy and Education explains and offers insights into what a democratic classroom is and is not. What a democratic classroom is and is not is implicitly stated in the following excerpt by John Dewey:

"Since education is a social process, and there are many kinds of societies, a criterion for educational criticism and construction implies a particular social ideal....... an undesirable society, in other words, is one which internally and externally sets up barriers to free intercourse and communication of experience....a society which makes provision for participation in its good of all its members on equal terms and which secures flexible readjustment of its institutions through interaction of the different forms of associated life is in so far democratic (Dewey 1997: 99)."

In the above excerpt, Dewey (ibid) understood education as a social process thereby implicitly comparing a school to two forms of societies namely the undesirable society and the democratic society. On the one hand, the undesirable society is in this study understood as being an undemocratic classroom where freedoms of intercourse and communication are severely curtailed. On the other hand, Dewey's society that provides for participation in its goods of all its members on equal terms is in this study viewed as a democratic classroom. In this regard, the concept will help the researcher classify the grade 6 classrooms of Chibombo into democratic or undemocratic ones with respect to teachers' classroom language practices.

It has to be restated here that the limiting of intercourse and communication in this study is synonymous with symbolic violence whereas the free intercourse and communication characterised through the use of both home and school languages is synonymous with translanguaging. In practice, democratisation of the classroom will involve translanguaging as a pedagogical practice. Below is an attempt to explain the concept of translanguaging and later its antithesis, symbolic violence.

Garcia (2009a: 41) referred translanguaging to "the use of children's full linguistic repertoire to make meaning without thinking of the fact that they have one language that is different from the other." In a similar way, Canagarajah (2011: 401) defined Translanguaging as "the ability of multilingual speakers to shuttle between languages, treating the diverse languages that form their repertoire as an integrated system." Thus, in translanguaging, languages are treated as one single system and not as separate entities; a view that reflect language as a socio-practice. Considering its literal morphological and semantic representation, Simachenya (2017: 14) summarised translanguaging as a derivative of "two linguistic units "trans" and "languaging" which he literally defined as moving across languages." Therefore, in a multilingual classroom, translanguaging implies a pedagogical language practice of alternation between languages viewed not as separate entities but as a single unit and as a meaning making resource.

In the classroom, translanguaging may involve students listening to information in one language and explaining the gist of it orally in another or reading a text in one language and talk about it in another (Garcia, 2009). For instance, a teacher may teach a maths lesson in English and then gives the exercise in a local language or in both. The teacher may also give freedom to the learners to take their notes in their own language. The other example is that of a teacher asking a question in the local language but gives freedom to pupils to give answers in a language of their choice. In this way, translanguaging as a pedagogical language practice enables certain concepts to be reinforced through repetition in several languages and clarified in much more detail as opposed to using one language (Hassan \& Ahmed, 2015: 26). In this research study therefore, translanguaging was the lenses through which teachers' language practices were analysed.

On the other hand, symbolic violence is one of the concepts derived from Pierre Bourdieu's (19302002) theory on language, power, and the reproduction of dominant language ideologies. He argued that languages do not exist for the sole purpose of communication but they function as a form of capital or power. It is for this reason that Bourdieu and Passeron (1990) viewed education as the vehicle through which the state can legitimize and control the linguistic market. This is done through legitimizing one language over others; meaning that some languages are granted official status while 
others become unofficial or illegitimate. It was from this view of legitimizing a language over others that Bourdieu (1977) introduced the concept of symbolic violence which he defined as the gentle, invisible violence that is not recognised as such. However, significant to our study is Bourdieu's (1990) reference of symbolic violence to a situation in which the standard variety or dominant language is legitimized through institutionalised discourse of education while the rest of the varieties or languages become illegitimate and excluded from official discourses.

Symbolic violence manifestations abound. According to students' perspective, it manifests itself through unequal chances depending on ethnic and linguistic background, and through the authoritarian style of imparting knowledge emphasised by the pedagogical attitudes encountered in some teachers (Bujorean, 2016). From the teacher's point of view, symbolic violence manifests itself in the way power is imposed through curricular policies and managerial decisions and through reduced acknowledgement of linguistic diversity (ibid). Its consequential implications are manifold as illustrated in the excerpt below by Meier (2002: 15)

... what the most successful students had going for them was that even in kindergarten, with their hands eagerly raised, they were ready to show off their school smarts. Starting on day one, certain forms of knowledge and skill - the stuff they've eagerly brought with them from home - was confirmed and honored, thus increasing their self-confidence to take still more risks. But many other students never found a replacement for a school and teacher who didn't recognize their genius, who responded with a shrug or a look of incomprehension as they offered their equally eager home truths. They too soon learned that in school all they could show off was their ignorance. Better to be bad, or uninterested, or to just silently withdraw.

Based on the above excerpt, the consequential negative effects of symbolic violence are that it reduces learners' self-confidence leading to their being uninterested and to silent-withdrawal behaviours. It severely curtails learners' participation in class activities especially those learners whose languages are neither recognised nor respected. In this study, the concept of symbolic violence helped analyse teachers' language practices and the learners' involvement in classroom activities.

By structure of language policy in Zambia, the education system has adopted a transitional bilingual language education system. Bilingual Education has both proponents and opponents. One major argument against bilingual education has been that it does not develop English rapidly enough because of its emphasis on the native language. However, this argument has been overwhelmingly rejected based on the research findings which have revealed that a strong native language foundation acts as a support in the learning of the second language, making it easier and faster; and that most of the learning that goes on in the native language readily transfers to the second language (Cummins, 1981; Garcia, 2009). Another argument held against bilingual education for minority children is that bilingualism confuses the mind and retards cognitive development. However, current research shows that there is no such thing as retardation caused by bilingualism. If anything, the development of a second language can have positive effects on thinking skills as Cummins (1976) postulated in his threshold theory. Cummins hypothesis has been tested and proved right by some researchers like Ricciardelli (1992, 1993) and Peal and Lambert (1962)

Ricciardelli $(1992,1993)$ conducted two studies to determine the influence of bilingualism on the children's cognitive abilities and creativity. The first study had 57 Italian-English bilingual and 55 English monolingual children aged five to six. The study showed that bilingual children proficient both in Italian and English languages significantly performed better than children who were proficient only in English. The second study was conducted in Rome with 35 Italian-English bilingual and 35 Italian monolingual children aged five and six. Similarly, bilingual children proficient in both Italian and English out-performed their monolingual counterparts proficient only in Italian language on word reading. The result overwhelmingly revealed high cognitive achievement by bilingual children over monolingual children.

The study done by Pearl and Lambert (1962) also revealed similar results. Pearl and Lambert (ibid) studied the effects of bilingualism on the intellectual functioning of 10 year-old children from six Montreal schools. They found that instead of suffering from "mental confusion" bilinguals were profiting from a language asset. They concluded that "intellectually, the bilinguals' experience with two language systems seemed to have left them with a mental flexibility, superiority in concept formation, and a more diversified set of mental abilities" (Pearl and Lambert 1962:20) 
The foregoing studied multilingual classrooms revealed positive cognitive advantages for bilingual learners because the linguistic diversities of its learners were recognised and respected. As mentioned earlier in the introduction, the pedagogical language practice associated with the recognition and the respect for linguistic diversity in the classroom is translanguaging. One of its advantages is that "it enables certain concepts to be reinforced through repetition in several languages and clarified in much more detail as opposed to using one language" (Hassan. N and Ahmed K, 2015: 26); and thereby promoting a deeper understanding of the subject matter, the development of the weaker language and the linking of home and school (Baker, 2011)

The above mentioned benefits of translanguaging matches the study carried out in Tower Hamlets by Kenner et al. (2008) cited by Nasima Hassan and Kamal Ahmed (2015) which examined the response of second and third-generation British Bangladeshi children who were given the opportunity to apply their full linguistic repertoire within the mainstream curriculum. The outcome of the study revealed conceptual transfer, meta-linguistic awareness and, more significantly, a deepened understanding of the curriculum. Contrary to the deficit models in bilingual learning held in the past, the study revealed cognitive advantages and cultural benefits of such pedagogy (Baker, ibid).

Translanguaging also increases comprehension in the context of other minority languages as reported by Lowman et al. (2007) that the New Zealand Maori literacy levels increased when students were allowed to use their first language to process and analyse texts that were in Maori. Similarly, in the context of a Catalan university in Spain, Llurda Cots and Armengol (2013) reported the increase in comprehension of text when English and Catalan languages were used to support students' comprehension in an English-medium class. Like the studies mentioned above, the Finnish National Board of Education Report (2011), cited in Mwanza (2012: 11-12), whose aim was to ascertain the factors that contributed to the Finish having high literacy levels in the world, revealed that even a small number of immigrants' children were given an opportunity to learn to read in their own mother tongue (including Swedish speaking minority).

The foregoing studies revealed conceptual transfer, meta-linguistic awareness and increased comprehension because the schools employed Dynamic bilingualism (Garcia, 2009) where the use of two or more languages for meaning making is a norm rather than an exception. However, the present study was done in Zambia with a transitional bilingual education program anchored on monoglossic ideology in which the use of multiple languages in the classroom for meaning making is severely curtailed and therefore, undemocratic.

\section{Methodology}

Methodologically, the study utilised the Sequential Explanatory Research Design; a mixed methods approach that involves the collection and analysis of quantitative data first and then qualitative data (Creswell, 2009). The quantitative approach was used mainly through a questionnaire to collect data on the sociolinguistic contexts of the schools where the study was conducted while the qualitative approach was used for classroom lesson observation to observe how teachers delivered the content in different subject areas in grade 6 when teaching multilingual learners. The idea here was to focus on classroom language practices and see to what extent the observed practices were linguistically democratic. Qualitative data collection also involved interviews with selected grade 6 teachers in order to ascertain their preferred language practices in the classroom. Triangulation of data collection provided detailed information on the multilingual nature of the classrooms, and on teachers' and learners' language practices and preferences in the classroom. Purposive and simple random sampling techniques were used to come up with 260 respondents of which 60 were grade 6 teachers and 200 were grade 6 pupils from 12 different schools. Quantitative data was analysed using the Statistical Package for Social Sciences (SPSS) while lesson observation and interview data was analysed thematically according to research objectives. The lessons were recorded and transcribed. Deliberately chosen portions of the lessons were picked for presentation and discussion.

\section{Presentation of Results}

\subsection{Multilingual Nature of the Sampled Classrooms}

Teachers were asked to state their familiar local language in order to find out if teachers' linguistic abilities and repertoires correlated with the languages widely spoken by the learners. The following are the first languages (mother tongue) of the teachers: 
Democratization of the Classroom through Teachers' Language Choices and Practices in Multilingual Classrooms of Zambia

Table1. The first language or the mother tongue of teachers

\begin{tabular}{|c|c|c|c|c|c|}
\hline \multicolumn{7}{|c|}{ Teachers' first language } \\
\hline & & Frequency & Percent & Valid Percent & C. Percent \\
\hline \multirow{4}{*}{ Valid } & Tonga & 14 & 23.3 & 23.3 & 23.3 \\
\cline { 2 - 6 } & English & 6 & 10.0 & 10.0 & 33.3 \\
\cline { 2 - 6 } & Lenje & 4 & 6.7 & 6.7 & 40.0 \\
\cline { 2 - 6 } & Bemba & 24 & 40.0 & 40.0 & 80.0 \\
\cline { 2 - 6 } & Nyanja & 9 & 15.0 & 15.0 & 95.0 \\
\cline { 2 - 6 } & Others & 3 & 5.0 & 5.0 & 100.0 \\
\cline { 2 - 6 } & Total & 60 & 100.0 & 100.0 & \\
\hline
\end{tabular}

The information given in the above table reveals that 40 percent of the teachers have Bemba as their first language followed by Tonga at 23 percent. The rest, in descending order, are Nyanja at 15 percent English at 10 percent, Lenje at 7 percent and others at 5 percent. The "other languages" (5 percent) mentioned in the interviews with teachers were Namwanga, Lozi and Kaonde.

Like in the questionnaire, most of the interviewed teachers stated Bemba, Tonga and Nyanja as their first languages. Other stated first languages were Namwanga and Lozi but none of the interviewed teachers stated Lenje as his or her first language. Below is what some teachers said:

I am Bemba by tribe and I spoke Bemba at home. But I am also able to speak Lenje because the head teacher forced me to learn Lenje so that I can help the learners in class (Teacher 1).

My first language is Namwanga but in grade 8 I stayed with my elder brother in Kabwe where I learnt Bemba. When I was posted to this area, I started learning Tonga and Lenje. It is half half now (Teacher 13).

Learners were also asked to state the language they used at home. This was done in order to find out if learners' home linguistic abilities and repertoires correlated with the designated languages of instructions in school namely Tonga and English. The following are the first languages of the learners:

Table2. The mother tongue of the learners or the languages learners use at home

\begin{tabular}{|c|c|c|c|c|c|}
\hline \multicolumn{7}{|c|}{ The language I use at home } \\
\hline & & Frequency & Percent & Valid Percent & C. Percent \\
\hline \multirow{4}{*}{ Valid } & Tonga & 32 & 16.0 & 16.0 & 16.0 \\
\cline { 2 - 6 } & English & 5 & 2.5 & 2.5 & 18.5 \\
\cline { 2 - 6 } & Lenje & 58 & 29.0 & 29.0 & 77.5 \\
\cline { 2 - 6 } & Bemba & 46 & 23.0 & 23.0 & 93.0 \\
\cline { 2 - 6 } & Nyanja & 45 & 22.5 & 22.5 & 100.0 \\
\cline { 2 - 6 } & Others & 14 & 7.0 & 7.0 & \\
\cline { 2 - 6 } & Total & 200 & 100.0 & 100.0 & \\
\hline
\end{tabular}

The information presented in the above table reveals that 29 percent of the learners used Lenje at home, 23 percent used Bemba, 22.5 percent used Nyanja, 16 percent used Tonga, 7 percent used other languages and 2.5 percent used English. In short, the home languages spoken by most of the pupils were Lenje, Bemba, Nyanja and Tonga while the least spoken home language was English.

Additionally, pupils were asked about the language they spoke when playing outside the classroom. This was particularly important because the home language and the language of play are not necessarily synonymous. Thus, regarding the language of play of the sampled learners, the following were their responses:

Table3. The language of play for the learners

\begin{tabular}{|c|c|c|c|c|c|}
\hline \multicolumn{6}{|c|}{ The language I speak with my friends } \\
\hline & & Frequency & Percent & Valid Percent & C. Percent \\
\hline \multirow{4}{*}{ Valid } & Tonga & 14 & 7.0 & 7.0 & 7.0 \\
\cline { 2 - 6 } & English & 3 & 1.5 & 1.5 & 8.5 \\
\cline { 2 - 6 } & Lenje & 76 & 38.0 & 38.0 & 46.5 \\
\cline { 2 - 6 } & Bemba & 47 & 23.5 & 23.5 & 70.0 \\
\cline { 2 - 6 } & Nyanja & 58 & 29.0 & 29.0 & 99.0 \\
\cline { 2 - 6 } & Others & 2 & 1.0 & 1.0 & 100.0 \\
\cline { 2 - 6 } & Total & 200 & 100.0 & 100.0 & \\
\hline
\end{tabular}

International Journal of Humanities Social Sciences and Education (IJHSSE) Page | 65 
The data in the table above shows that 38 percent of the learners spoke Lenje when at play followed by Nyanja at 29 percent. The rest in descending order are Bemba at 23.5 percent, Tonga at 7 percent and English at 1.5 percent.

For triangulation purposes, interviewed teachers were also asked to state the language of play for their learners. While learners gave their view, it was important that teachers indicate their learners' language of play. Below is what they said:

They (pupils) speak Bemba and Nyanja in class and when playing but it is difficult to know the dominant language of play (Teacher 10).

Many pupils here speak Lenje and there are some who speak Bemba and Nyanja especially those pupils from teachers' and civil servants' homes (Teacher 11).

Here it depends; those from civil servants' houses use Bemba at play while those from villages use Lenje when at play (Teacher 20).

\subsection{Teachers' Language Practices in the Sampled Classroom}

The second research objective sought to analyse teachers' language practices in selected grade six classrooms. Teachers were asked if they used more than one language when teaching. This question was about whether or not teachers translanguaged during classroom teaching. The following were their responses:

Table4. Teachers' opinion on if they used more than one language when teaching

\begin{tabular}{|c|c|c|c|c|c|}
\hline \multicolumn{7}{|c|}{ I use more than one language when teaching } \\
\hline & & Frequency & Percent & Valid Percent & C. Percent \\
\hline \multirow{4}{*}{ Valid } & Strongly agree & 20 & 33.3 & 33.3 & 33.3 \\
\cline { 2 - 6 } & Agree & 36 & 60.0 & 60.0 & 93.3 \\
\cline { 2 - 6 } & Disagree & 3 & 5.0 & 5.0 & 98.3 \\
\cline { 2 - 6 } & Strongly disagree & 1 & 1.7 & 1.7 & 100.0 \\
\cline { 2 - 6 } & Total & 60 & 100.0 & 100.0 & \\
\hline
\end{tabular}

The data above shows that 33.3 percent of the respondents strongly agreed that they used more than one language while 60 percent agreed. Further, while 5 percent disagreed, 1.7 percent strongly disagreed. However, when the question was asked in a different way, responses also changed. The other question was whether teachers allowed the use of other languages in the classroom other than the official medium of instruction (English). The following were the responses:

Table5. Teachers' opinion on encouraging the use of local languages in the classroom

\begin{tabular}{|c|c|c|c|c|c|}
\hline \multicolumn{6}{|c|}{ I encourage pupils to use local languages in the classroom } \\
\hline & & Frequency & Percent & Valid Percent & C. Percent \\
\hline \multirow{4}{*}{ Valid } & Strongly agree & 8 & 13.3 & 13.3 & 13.3 \\
\cline { 2 - 6 } & Agree & 20 & 33.3 & 33.3 & 46.7 \\
\cline { 2 - 6 } & Disagree & 30 & 50.0 & 50.0 & 96.7 \\
\cline { 2 - 6 } & Strongly disagree & 2 & 3.3 & 3.3 & 100.0 \\
\cline { 2 - 6 } & Total & 60 & 100.0 & 100.0 & \\
\hline
\end{tabular}

The data from the table above shows that while 13.3 percent of the respondents strongly agreed that they allowed the use of local languages in the classroom, 33.3 percent agreed to doing so. On the other hand, while 50 percent disagreed; meaning that they did not allow the use of other languages besides English in the classroom, 3.3 percent of the respondents strongly disallowed the use of other languages besides English.

The qualitative data from interviews revealed that many teachers agreed that they used other languages besides English. Below are some of their responses:

I first introduce the topic in English then Bemba. I use Bemba to explain difficult words or sentences that learners do not understand. I use Bemba to explain and help them learn (Teacher 3).

The main language is English but to stress a point or to simplify a concept, I use Bemba and Tonga. When emphasising a point I use the language that learners are able to understand, I often translate from English to Bemba and Tonga (Teacher 7). 
In order to ascertain teachers' views indicated in the questionnaires and during interviews in which they stated that they used more than one language when teaching, 6 lesson observations were done. However, only three lessons and the excerpts of the transcribed lessons are as shown below:

\section{Excerpt 1: English lesson on "Index and Dictionary." (Teacher 3)}

Teacher: And the same can be found muma (Bemba: on the) pages ayengi (many) aini (not so)...But for the table of content yena taba (for it they don't)... hnm.... what is found generally muliyo (at that) page twaumfwana aini (we have agreed not so)...And the dictionary....na dictionary tamwaishiba? (even the dictionary you don't know?)

Pupils: Aweee twaliishiba (Bemba: no, we know it)

Teacher: Uwalanjebako dictionary nani? (who will tell me what a dictionary is)..... what is a dictionary? munjebele ati mwalishiba dictionary (Bemba: you told me that you know a dictionary)....Mwacilafwaya ukuimona? (do you want to see it?)

Pupils: tatwaishiba mu Cisungu (Bemba: we don't know it in English)

Teacher: Kuti mwalanda nangu mu Cilenje nangu mu Cinyanja (you can say it in Lenje or Nyanja)....(no answer from the pupils as the teacher went on distributing text books).

\section{Excerpt 2: Mathematics lesson on "Division and Multiplication" (Teacher 12)}

Teacher: So when writing.....pakulemba (Bemba: when writing ).....you write on top of 7...... this one......not iyi apa (Bemba: not this one) but the first 7. Then step 2, what are we going to do? Wacita viyani Chansa (pseudo name of the pupil)? (Lenje: what are we going to do, Bwalya (pseudo name of the pupil)).....we have written our answer....step 2 twacita viyani? (Tonga: what do you do?)... Tulecita shani? (Bemba: what do we do?)

Pupils: (Silence)

Teacher: Ok, we are going to multiply 2 by 3, tefyo? (Bemba: not so?) 2 multiply by $3 \ldots$ Maxwell(pseudo name of the pupil)?..

Pupil: six (6)

Teacher: Where are we supposed to write 6? Tulelemba apa olo apa? Tulelemba aba or aba? (Bemba: where do we write, here or there?)

\section{Excerpt 3: Science lesson on "Teenager Pregnancies and social problems" (Teacher 15)}

Teacher: Today we are going to discuss about teenage pregnancy and social problems. Who can tell me what we discussed last time?

Pupils: (Silence)

Teacher: Ok last time we talked about the features ofu (of) Pregnancy. So today we are going to talk about..abauuti (about) teenage pregnancy.....We are going to talk abauuti (localised English for about) what happens to teenagers... what happens to the peop... teenagers when they get pregnant...are we together? And the consequences and risks ...are we together? Before we start talking about teenage pregnancy, can we go through what we learnt last time we met....we talked aboutii (localised English) pregnancy.. what is pregnancy... Chilekwa! (pseudo name of the pupil) (calls the name of the pupil)

Pupil: (as the exercise book was opened she said....) pregnancy is the time during..eeeh during when eeeh the baby grows inside the mother's womb.

\section{Discussion OF FINDINGS}

\subsection{Multilingual Nature of the Sampled Classrooms}

The findings were that 8 languages were represented in the classrooms of Chibombo district. These were Tonga, Bemba, Nyanja, Lenje, English, Namwanga, Lozi and Kaonde. Majority of the teachers, according to the findings have Bemba at 40 percent as their first language followed by Tonga at 23 percent, Nyanja at 15 percent, and English at 10 percent and Lenje at 7 percent. The findings concerning the learners' first language revealed slight different results where Lenje was dominant at 
29 percent followed by Bemba at 23 percent, Nyanja at 22.5 percent, Tonga at 16 percent and English at 2.5 percent.

What is interesting is that while Lenje was dominant at 29 percent, it was striking to find Bemba and Nyanja at 23 percent and 22.5 percent respectively accounting for a cumulative percentage of 45.5 percent of the pupils. The interesting issue is that in terms of relatedness of languages, Bemba and Nyanja are not really mutually intelligible to Tonga which is the official regional language of Chibombo district. Additionally, apart from Lenje and Tonga which are mutually intelligible and account for a total of 45 percent of the pupils represented in the sampled schools, 55 percent of the respondents spoke or were familiar with other languages other than the ones designated for the area in which the schools are situated.

Another interesting observation from the findings is the statistics of English either as a first language or a language of play. While English is the first language to 2.5 percent representing 5 pupils out of 200 , it is a language of play to 1.5 percent (representing 3 pupils out of 200). Interestingly, this is the official medium of instruction from grade 5 onwards yet statistics show that only 1.5 to 2.5 percent could speak English. This is not surprising considering the 2010 census which showed that only 2.7 or 3 percent of the Zambian population could speak English. What this suggests is that there are a lot of pupils who, even at grade six cannot speak and understand English at a desirable level. What the above findings have revealed are both the areas of conventionality and contradictions.

Conventionality in the sense that there are similarities between the findings and the argument that (a) Zambia is a multi-ethnicity and multilingual country (Kashoki, 1978) (b) that all Zambia's classrooms are inherently multilingual (Mwanza, 2017), and (c) that most Zambians are polyglots as they are able to speak more than one language (Williams, 1998; Banda, 1995).

The contradictions were characterised by the mismatch between the monolingual Language in Education Policy and the actual multilingual composition of the classrooms. The contradiction here is that the language policy stipulates the use of English in the upper primary schools whereas the findings showed that only 3 percent of the learners speak English. It is in such context that Haugen (2009) argued that education policies are normally characterized by contradictions and not by progression or retrogression. The above contradiction is not peculiar to Chibombo district as similar results were found in Chongwe where Mubanga (2012) established that while Cinyanja was viewed as the familiar language and therefore medium of instruction, children were familiar to Soli language. Similarly, Mwanza (2012) found that although Cinyanja was the officially sanctioned language in Lusaka, both teachers and pupils were not familiar with the language of instruction.

The implication of the findings is that the monolingual ideology of language zoning is weak as it does not really reflect the language(s) spoken in an area. The zoning of language turns to assume that languages are static and that the linguistic situation of an area is static. For instance, the assumption that the language familiar to the majority of the people in Chibombo district is Tonga is a fallacy as the said language only accounted for 16 percent of the 200 pupils who were sampled from 12 primary schools in Chibombo. Another example is that of English as the designated medium of instruction in the upper primary schools which however accounted only for 3 percent of the learners. Therefore, it is not out of context here to suggest that the Zambian language in education policy needs to be revisited, amended and to recommend language practices which resonate well with the language situation in schools. In fact, Banda and Mwanza (2017) argued that the arbitrary zoning of language and its corresponding monolingual ideologies were a contributing factor to low literacy level in Zambia.

\subsection{Teachers' Language Practices in the Sampled Classroom}

The quantitative findings revealed that while majority of the teachers at 93.3 percent used other languages apart from English to help learners learn and that 46.6 percent of the teachers encouraged learners to use local languages, a few teachers at 6.6 percent did not use local languages and that 53.3 percent of the teachers did not encourage learners to use local languages in the class. The quantitative data is echoed in the qualitative data collected through interviews and lesson observations. Many interviewed teachers indicated that they used both English and local languages when teaching. Similarly, data from lesson observation showed that out of the 6 teachers observed, four used local languages and English as the rest (two teachers) used English only. The interesting finding is that the two teachers who used English only had their English blended with the local English and Standard 
British English as shown in excerpt 3. Thus, language practices in the classrooms were mostly characterised by translanguaging.

As interviewed teachers were not familiar with translanguaging as a pedagogical language practice for multilingual classrooms, they mentioned code switching and translation as the language practices they employed when teaching multilingual classrooms. According to Tse (1996) and Garcia (2009) translanguaging practices include code-switching, translating, and language brokering, or interpreting between culturally and linguistically diverse individuals. The other language practice that emerged from lesson observations was nativisation of English or Zambianisation of English.

In reference to code switching, teachers stated that they used more than one language when teaching. In the classes that were observed, the findings were that most of the teachers translanguaged by alternating between English and local languages such as Bemba, Nyanja and Lenje as shown in excerpts 1 and 2. Another pedagogical language practice revealed in the study was Translanguaging through translation. Lin (2008: 17) stated that translation involves "expressing the sense of words or text in another language". Teacher 12 for example in excerpt 3 rephrased and repeated his questions from English to Bemba, Nyanja, Tonga and Lenje. He was teaching mathematics, and the topic was on multiplication and division. At some point in the lesson, he asked the same question four times in different languages. As he translanguaged through translation, he asked the answer for "seven divide by two" in four different languages. In so doing, he communicated the question to learners who were familiar with Bemba, Lenje, Tonga and English. In an event that a particular student understood more than one of the four languages, the use of those languages would enhance comprehension and present various ways of understanding reality. As the teacher repeated the questions in different languages, more hands were raised, indicating that learners understood the questions in their local languages. Surprisingly, the learners used English when answering questions in the lesson taught by teacher 12, and even the pupil who was called in front to solve a division problem did so in English. This means that learners who answered the questions understood both English and the local languages the teacher used. It is in this view that Hassan and Ahmed (2015: 26) stated that "translanguaging as a pedagogical language practice enables certain concepts to be reinforced through repetition in several languages and clarified in much more detail as opposed to using one language".

The other pedagogical language practice revealed in this study as mentioned earlier was "nativisation of English (Zambianisation of English) which in this study means the blending of English letters and words with local words for them to sound like words in local language. This is because almost all the words in Zambian local languages have open syllables; cvcv (mama for grandmother) and cccv (mbwa for a dog) for example. Contrary to closed syllables such as cvc (as in "bad") and cccvcc (as in strict), open syllables end with vowels and to suit these closed syllabic words to the local context, teachers or learners have a tendency to insert vowels to English words (Kashoki, 1978; Kangwa, 2007; MoE, 2015).

In the classes that were observed (see excerpt 3 above), teachers where heard pronouncing words such as "have" =/haavu/, "of" =/ofuu/, "what" =/waati/, "about" =/abauuti/, "come" =/kaamu etc. They did this to make or help learners associate the English words with local words or accent, in a way helping them connect English words with words in local languages. In some cases, it was done to invite or entice learners to complete the sentence like in "yesterday we talked abauuti... flowers.... We talked abauuti..." in which case the learners would give a chorus answer "flowers." In other cases, it was applied when asking question as in "they have waati...?" There were some instances also when nativisation of English was used to entice learners to repeat what the teacher had previously said like in "so when a man and woman grow or they fall in love, they have babies....they have waati...? And the learners would chorusly repeat "babies". In addition, teachers used this kind of language practice to encourage learners to repeat words and speak louder or correctly as in "people who have unprotected sex havuu......pregna, have waati....pregna, havuu....pregnancy”.

It is important to state here that the translanguaging practised by teachers was "semi-translanguaging" as it did not constitute fully translanguaging as a whole for some reasons. To begin with, Garcia (2009) suggested that translanguaging may involve the reading of a text in several languages and talk about it in different languages. In contrast, the findings showed that all the text books in all the observed classes were in English and that all the readings were done in one language. Secondly, contrary to the suggestion by Garcia (ibid) that a lesson can be given in one language and the 
exercises in another language, all the exercises that teachers gave to learners were in English. Thirdly, while Garcia (ibid) added that learners can have the lesson in the official language and take notes in their own languages, all the writings on the board and in the exercise books of learners that were checked were in one language - English. Lastly, translanguaging involves both learners and teachers using all the languages at their disposal for meaning making (ibid). Contrary to this view, the study revealed that 53.3 percent of teachers translanguaged but did not allow learners to use local languages. The translanguaging that this study revealed is therefore here referred to as "Semi - Translanguaging" as it existed mainly in spoken form and not in written form.

Semi -translanguaging here implies the presence of symbolic violence. As revealed in this study, 53.3 percent of the teachers used local languages but did not allow learners to use local languages, and that 6.7 percent of the teachers neither used local languages nor allowed learners to use local languages. These actions by teachers, apart from revealing the presence of symbolic violence, they also revealed the power relation that existed between teachers and learners; the relationship between the dominant and the dominated controlled weak group (Mwanza, 2016). In this case, the foregoing mentioned teachers dominated and controlled the learners' choice and use of languages thereby symbolically violating their rights to access knowledge or contribute to classroom discussions.

In the broader conceptualisation of eclecticism to teaching, a translanguaging teacher is an eclectic teacher because they realise that both mother tongue and the official languages can co-work in meaning making in the classroom (Mwanza, 2017). However, it is important to note here that for classroom practices such as translanguaing to be implemented, teachers and pupils ought to have positive attitudes towards local languages. As Mwanza (2017) put it, teacher attitudes are key to the successful implementation of any curriculum or policy and indeed achievement of any educational objective.

The other implication coming out of the findings is that teachers are not adequately prepared in multilingual language practices. Manchishi and Mwanza (2013) observed that most teachers in Zambia had a lot of content knowledge but lacked practical classroom skills. In Manchishi and Mwanza (2016) also criticised the manner in which teacher training strategies such as peer teaching were conducted during teacher training in Zambia. In a nutshell, if teachers are to apply themselves in these diverse linguistic contexts, there is need for both capacity building in teachers and change of language attitudes among some teachers.

\section{CONCLuSiONS}

It has been confirmed that multilingualism and linguistic diversity in Chibombo district is a reality. However, while the officially recognised regional language is Tonga and the language of medium of instruction at grade 5 is English, the majority of the pupils in the sampled schools spoke Lenje, Bemba and Nyanja. This has shown that language zoning in Zambia is problematic as it does not reflect the actual sociolinguistic situation in some parts of the country such as Chibombo (see also Banda and Mwanza, 2017). Additionally, while some teachers democratised their classrooms through the adoption of translanguaging as pedagogic practice, others insisted on monolingual language practices which resulted in symbolic violence with pupils having access to the classroom but not learning. In other words, while some teachers held positive attitudes towards local languages and translanguaging, others did not.

\section{REFERENCES}

[1] Africa, H.P. (1980). Language in Education in a Multilingual state: A case Study of the Role of English in the Education System in Zambia. Phd Thesis, University of Toronto.

[2] Baker, C. (2006). Foundations of bilingual education and bilingualism (4th ed.). Clevedon ; Buffalo: Multilingual Matters.

[3] Baker, C. (2011). Foundations of Bilingual Education and Bilingualism, 5th edn. Bristol, UK: Multilingual Matters.

[4] Banda, F. (1995). The meaning to Grammar Hypothesis of Zambian English: Implications for Classroom Instruction in Multilingual Context. PhD Thesis, Free University, Brussels.

[5] Banda, F and Mwanza, D. S. (2017). Language-in-education policy and linguistic diversity in Zambia: An alternative explanation to low reading levels among primary school pupils. In Banja, Madalitso Khulupirika (ed.). Selected readings in education, 109-132. Lusaka: University of Zambia Press. 
[6] Bernstein, B. (1973). Class, Codes and Control 3: towards a theory of educational transmissions. London.

[7] Bernstein, B. (1975). Towards a Theory of Educational Transmissions (Vol. 3). London: Routledge \& Kegan.Paul.

[8] Bernstein, B. (1990). The structuring of pedagogic discourse: Class, codes \& control, Volume IV. London: Routledge.

[9] Bujorean, E. (2016). Objective Violence and Symbolic Violence in Schools. Studies on the Perception of High-school Students. International Journal of Social and Educational Innovation (IJSEIro) Volume 3 / Issue 5/ 2016

[10] Bourne, J. (2006). Official pedagogic discourses and the construction of learners' identities. School of Education, University of Southampton Southampton SO17 1BJ, U.K.

[11] Bourdieu, P. (1977 ). Outline of a Theory of Practice. Trans. Richard Nice. Cambridge, UK: Cambridge University Press.

[12] Bourdieu, P. (1986). The Forms of Capital. Pp. 241-258 in Handbook of Theory and Research for the Sociology of Education. Ed. John G. Richardson. New York: Greenwood Press.

[13] Bourdieu, P. (1990). The Logic of Practice. Stanford: Stanford University Press

[14] Bourdieu, P. (1991). Language and Symbolic Power. Trans. Gino Raymond and Matthew Adamson. Cambridge, MA: Harvard University Press.

[15] Canagarajah, Suresh. (2011). Codemeshing in academic writing: Identifying teachable strategies of translanguaging. The Modern Language Journal 95 (iii), 401-417.

[16] Creswell, J. W. (2009). Research Design: Qualitative, Quantitative and Mixed Methods Approaches. (3rded.). Los Angeles: SAGE Publications

[17] Cummins, J. (1979). Cognitive/Academic Language Proficiency, Linguistic Interdependence, the Optimal Age Question and Some Other Matters. Working paper on Bilingualism, 19, 197-205.

[18] Cummins, J. (1981). The role of primary language development in promoting educational success for language minority students. In California State Department of Education (Ed.), Schooling and language minority students: A theoretical framework (pp. 3-49). Los Angeles: Evaluation, Dissemination and Assessment Center, California State University.

[19] García, O. (2009). Bilingual Education in the 21st Century: A Global Perspective. Malden, MA: WileyBlackwell.

[20] García, O. (2009). Bilingual Education in the 21st Century: A Global Perspective. Chichester: Wiley Blackwell.

[21] Garcia, O. and Guevara, R. T. (2010). Handbook of Latinos and Education : theory, research and practice. New York.

[22] García, O., and W. Li. (2014). Translanguaging: Language, Bilingualism and Education. New York: Palgrave Macmillan.

[23] Gordon, R. (2014). Language of Education Planning in Zambia. Volume 3 Article 6, Linguistic Portfolios. St. Cloud State University

[24] Grotpeter, J.P. (1977). Historical Dictionary of Zambia. London: The Scarecrow Press.

[25] Hassan,N. and Ahmed, K. (2015). Exploring translanguaging: a case study of a madrasah in Tower Hamlets, University of East London. Vol.5. No 2. November 2015 pp. 23-28

[26] Haugen, C, R. (2009). Recontextualisation of Trainable Learning Strategies and Social Background. In Contexttualisations and Rcontextualisations of Discourse Equity in Education (pp. 143-167). Phd Thesis.Trandeheim: Norwegian University of Science and Technology

[27] Kangwa, N.K. (2007). A study of English-Derived Loanwords in Bemba, Master of Arts in Linguistic Science, University of Zambia.

[28] Kashoki, M. (1978). The Language Situation. In Ohannessian and Kashoki. 1978:9-46.

[29] Kumwenda, B. (2011). Initial Reading Performance in Nyanja in Multi-ethnic Classes: A case of Selected Schools in Chipata Urban. UNZA.

[30] Legere, K. ( 2002). Talking Freedom: Language and Democratisation in the SADC Region. Gamsberg Macmillan.

[31] Lewis, G. and Baker, C. (2012a) Translanguaging: Origins and Development from School to Street and Beyond. Educational Research and Evaluation: An International Journal on Theory and Practice 18: 641-654.

[32] Lewis, G. Jones, B. and Baker, C. (2012b) Translanguaging: Developing its Conceptualisation and Contextualization. Educational Research and Evaluation: An International Journal on Theory and Practice 18: 655-670. 
[33] Lin, A (2008). Bilingualism or Linguistic Segregation? Symbolic Domination, Resistance and Code Switching in Hong Kong Schools. In Linguistics and Education, 8, 49 - 84.

[34] Llurda, E, Cots, J. M, \& Armengol, L. (2013). Expanding language borders in a bilingual institution aiming at trilingualism. In H. Haberland, D. Lønsmann, \& B. Preisler (Eds.), Language alternation, language choice and language encounter in international tertiary education. Dordrecht, Netherlands: Springer Science+Business Media.

[35] Lowman, C., Fitzgerald, T., Rapira, P., and Clark, R. (2007). First language literacy skill transfer in a second language learning environment: Strategies for biliteracy. Set 2, 24-28.

[36] Manchishi, P. C. and Mwanza, D.S. (2016). Teacher Preparation at the University of Zambia.: Is Peer Teaching Still a Useful Strategy? International Journal of Humanities Social Sciences Educations (IJHSSE). 3 (11) 88 - 100.

[37] Manchishi, P.C and Mwanza, D.S. (2013). The University of Zambia School Teaching Experience: Is It Effective? Excellence in Higher Education. 4 (2), 61-77.

[38] Meier, D. (2002). In schools we trust: Creating communities of learning in an era of testing and standardization (Boston: Beacon Press).

[39] Mengisteab, K. (1996). Globalization and auto-centricity in Africa's development in the $21^{\text {st }}$ century. Asmara, Eritrea: Africa World Press.

[40] Ministry of Education. (2013). Zambia Education Curriculum Framework 2013: Curriculum Development Centre P.O. Box 50092, Lusaka.

[41] Mubanga, V. (2012). Effects of the use of Cinyanja to teach initial Literacy in a predominantly Soli speaking area of Lwimba in Chongwe District. Dissertation in Master of Education in Literacy and Learning. University of Zambia

[42] Mwanza, S.D. (2012). The language of Initial Literacy in a Cosmopolitan Environment: A Case of Cinyanja in Lusaka District. Unpublished Masters Dissertation, School of Education, University of Zambia.

[43] Mwanza, D. S. (2016). A Critical Reflection on Eclecticism in the Teaching of English Grammar at Selected Zambian Secondary Schools. Unpublished PhD Thesis: University of Western Cape.

[44] Mwanza, D.S. (2017). Implications of Teachers' Attitudes towards Unofficial languages on English Language Teaching in Multilingual Zambia. Zambian Journal of Language Studies, 1 (1): 101 - 124.

[45] Mwanza, D.S. (2017). The Eclectic Approach to Language Teaching: Its Conceptialisation and Misconceptions. International Journal of Humanities Social Sciences and Education (IJHSSE). 4 (2): 53 67.

[46] Mwanza, D.S. (2017). Teachers' Understanding and Attitudes towards the Eclectic Method to Language Teaching in Zambia. Journal of Educational and Management Studies J. Educ. Manage. Stud., 7(1): 01-16.

[47] Open University, (2015). Multilingualism in the classroom TI-AIE : Milton Keyenes MK7 UK.

[48] Oxford, R. L. (1990). Language learning strategies: What every teacher should know. New York: Newbury House.

[49] Pacific Policy Research Center, (2010). Successful Bilingual and Immersion Education Models/Programs. Kamehameha Schools Research and Evaluation Division.

[50] Peal, E.; and Lambert, W. E. (1962). The relation of bilingualism to intelligence. Psychological Monographs General and Applied, Vol. 76, M27, Whole No. 546.

[51] Ruiz, R. (1984). Orientations in language planning. NABE Journal, 8, 15-34.

[52] Ruiz, R. (2010). Reorienting language-as-resource. In J.E. Petrovic (Ed.), International perspectives on bilingual education: Policy, practice, and controversy (pp. 155-172). Charlotte, NC: Information Age.

[53] Simachenya, M.M. (2017). Language Practices in a Multilingual Classroom Situation: A case of selected primary schools in Livingstone Urban. M.A. Dissertation. Lusaka. UNZA.

[54] Tse, L. (1996). Language brokering in linguistic minority communities: The case of Chinese-and Vietnamese-American students. Bilingual Research Journal, 20(3/4), 485-498. doi: 10.1080/15235882.1996.10668640

[55] Totemeyer, G. (1997). Glossary of electoral terms and related concepts. $2^{\text {nd }}$ Edition. Directory of Elections and Namibia Institute for Democracy.

[56] UNESCO (1964). Report of the UNESCO Planning Mission: Education in Northern Rhodesis. Lusaka: Government Printer.

[57] UNESCO (2003). Education in a multilingual world: UNESCO Education Position Paper 7, place de Fontenoy - 75007 Paris (France) www.unesco.org/education. 
[58] Williams, E. (1998). Investigating bilingual literacy: Evidence from Malawi and Zambia - Education Research Paper No.24, 1998, 99 p.

[59] Wodak, R. (2001). What CDA is it all about-a summary of its history, important concepts and developments. In R. Wodak., and M. Meyer (Eds.), Methods of critical discourse analysis (pp. 1-13). Thousand Oaks, CA: Sage Publications.

\section{AUTHORS' BIOGRAPHY}

Vigirio BWALYA has just completed Postgraduate Studies at the University of

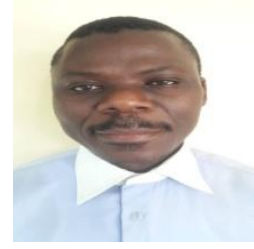
Zambia where he pursued Master of Education in Applied Linguistics degree. He obtained his Bachelor's degree in Education from Pontifical Urbaniana University in Rome. He also holds a Diploma and Certificate in TESOL (Teaching English to Speakers of Other Languages). His interests are in learning and teaching languages. $\mathrm{He}$ is currently (2019) doing missionary work in Bangladesh as a teacher of English to underprivileged children.

Citation: Vigirio Bwalya. “Democratization of the Classroom through Teachers' Language Choices and Practices in Multilingual Classrooms of Zambia ". International Journal of Humanities Social Sciences and Education (IJHSSE), vol. 6, no.5, 2019, pp. 60-73. doi: http://dx.doi.org/10.20431/2349-0381.0605006.

Copyright: (C) 2019 Authors. This is an open-access article distributed under the terms of the Creative Commons Attribution License, which permits unrestricted use, distribution, and reproduction in any medium, provided the original author and source are credited. 